\title{
SCADA data based condition monitoring of wind turbines
}

\author{
Ke-Sheng Wang $\cdot$ Vishal S. Sharma \\ Zhen-You Zhang
}

Received: 14 January 2014/ Accepted: 17 February 2014/Published online: 7 March 2014

(C) Shanghai University and Springer-Verlag Berlin Heidelberg 2014

\begin{abstract}
Wind turbines (WTs) are quite expensive pieces of equipment in power industry. Maintenance and repair is a critical activity which also consumes lots of time and effort, hence making it a costly affair. Carefully planning the maintenance based upon condition of the equipment would make the process reasonable. Mostly the WTs are equipped with some kind of condition monitoring device/system, which provides the information about the device to the central data base i.e., supervisory control and data acquisition (SCADA) data base. These devices/systems make use of data processing techniques/methods in order to detect and predict faults. The information provided by condition monitoring equipments keeps on recoding in the SCADA data base. This paper dwells upon the techniques/methods/algorithms developed, to carry out diagnosis and prognosis of the faults, based upon SCADA data. Subsequently data driven approaching for SCADA data interpretation has been reviewed and an artificial intelligence (AI) based framework for fault diagnosis and prognosis of WTs using SCADA data is proposed.
\end{abstract}

K.-S. Wang · Z.-Y. Zhang

Department of Production and Quality Engineering, Norwegian

University and Science and Technology, Trondheim, Norway

\section{S. Sharma $(\square)$}

Department of Industrial and Production Engineering, Dr. B .R. Ambedkar National Institute of Technology, Jalandhar, Punjab, India

e-mail: sharmavs@nitj.ac.in
Keywords SCADA data $\cdot$ Data-driven approaches · Artificial intelligence (AI) - Diagnosis and prognosis of wind turbines - Central monitoring system (CMS)

\section{Introduction}

Renewable energy source is playing an important role in the global energy mix, as a mean of reducing the impact of energy production on climate change. Wind energy made its first appearance thousands of years ago with the vertical axis windmills found at the Persian-Afghan borders around $200 \mathrm{BC}$ and the horizontal-axis windmills of the Netherlands and the Mediterranean following much later (1300-1875 AD). Gradual evolution and perfection of these systems were performed in the USA during the 19th century mainly for pumping water between 1850 and 1970. The first large wind machine to generate electricity of $12 \mathrm{~kW}$ was installed in Cleveland, Ohio, 1888. Towards the end of World War I, use of $25 \mathrm{~kW}$ machines throughout Denmark was widespread. More development of wind turbines (WTs) in the USA was inspired by the aerospace developments, while subsequent efforts in Denmark, France, Germany, and the UK (between 1935 and 1970) showed that largescale WTs could work. European developments continued after World War II and lots of developments have been made [1]. During the last thirty years, securities of energy supply and environmental issues have reheated the interest for wind energy applications. In addition, the challenge of wind energy applications is the target of $1,000 \mathrm{GW}$ of wind power by 2030 . Further the trend in future is towards producing big and offshore turbines. The future forecast is indicated that the demand for wind power will increase many folds in the years to come. The rated capacity and size will both increase in time to come. 


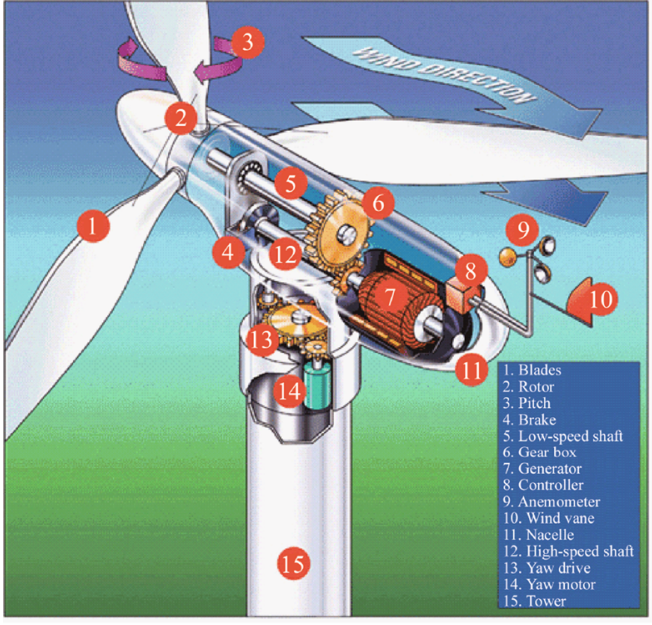

(a) Parts of WT

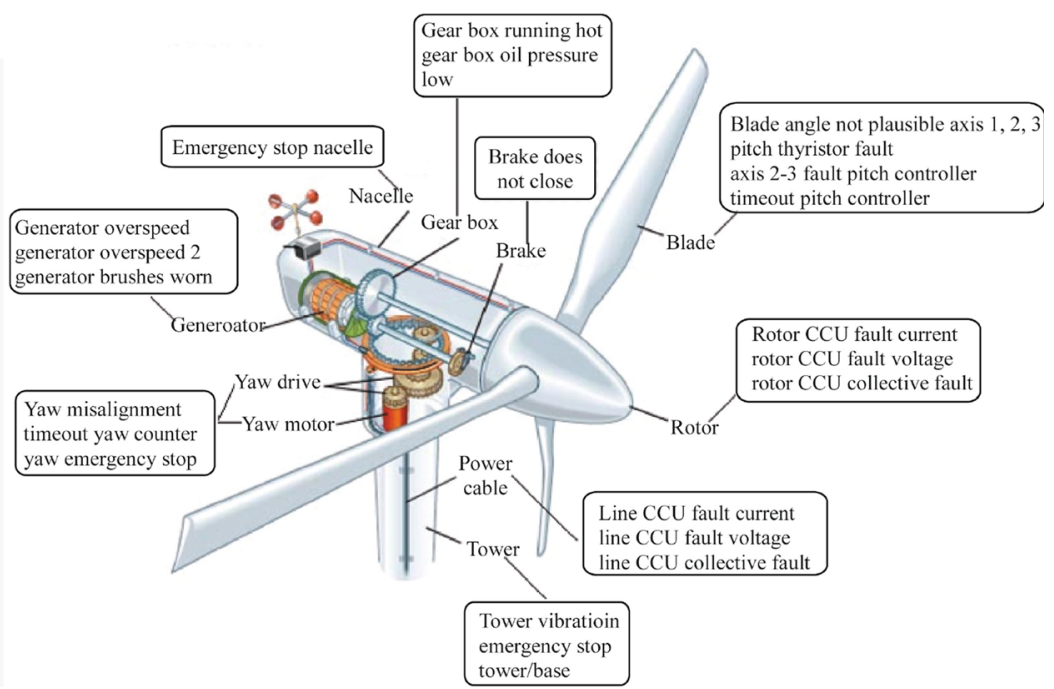

(b) CMS on WT [2]

Fig. 1 a Parts of WT b CMS on WT [2]

\section{Brief background}

\subsection{WTs}

A wind turbine (WT) is a machine used for converting the kinetic energy in wind into mechanical energy. WTs are mainly classified into two general types: horizontal axis and vertical axis. A horizontal axis machine has its blades rotating about an axis parallel to the ground. A vertical axis machine has its blades rotating about an axis perpendicular to the ground. There are a number of available designs for both and each type has certain advantages and disadvantages. However, compared with the horizontal axis type, very few vertical axis machines are available commercially. Further horizontal WTs are also of two types: upwind and downwind. In case of upwind WT the rotor is in the front of the unit. In order to keep it oriented into the wind, a yaw mechanism is needed. Also the extended nacelle is required to position the rotor far away enough from the tower, in order to avoid any problems with a blade strike. In a downwind turbine the rotor is on the back side of the turbine. The nacelle is designed to seek the wind, thus there is no need to have a separate yaw mechanism. The flexible blade could be used but this advantage may also be a disadvantage, as the flexing may cause fatigue to the blades. Tower shadow is a problem with downwind machines because the rotor blade is behind the tower. This may cause turbulence and lead to increased fatigue on the unit. Keeping in view the pros and cons of both types, mostly upwind WTs are used. The various parts of horizontal WT (see Fig. 1) and their purposes are indicated: 1: blades (two or three blades, wind blowing over the blades causes the blades to "lift" and rotate); 2: rotor (blades and the hub together); 3 : pitch (blades are turned out of the wind to keep the rotor from turning in winds that are too high or too low to produce electricity); 4: brake (disc brake which can be applied mechanically, electrically, or hydraulically); 5: low-speed shaft (turns at about $30 \mathrm{r} / \mathrm{min}$ to $60 \mathrm{r} / \mathrm{min}$ ); 6 : gear box (connects the low-speed shaft to the high-speed shaft in order to increase speed from $30 \mathrm{r} / \mathrm{min}$ or $60 \mathrm{r} / \mathrm{min}$ to about $1,200 \mathrm{r} / \mathrm{min}$ to $1,500 \mathrm{r} / \mathrm{min}$ for producing electricity); 7: generator (induction generator that produces 60-cycle AC electricity). 8: controller (starts or stops the WT at wind speeds of about $12.87 \mathrm{~km} / \mathrm{h}$ to $25.75 \mathrm{~km} / \mathrm{h}$ and $104.61 \mathrm{~km} / \mathrm{h}$ respectively; 9: anemometer (measures the wind speed and transmits wind speed data to the controller); 10: wind vane (measures wind direction and communicates with the yaw drive to orient the turbine); 11: nacelle (the rotor attaches to the nacelle, which sits atop the tower and includes the gear box, low and highspeed shafts, generator, controller, and brake, a cover protects the components inside the nacelle); 12: high-speed shaft (drives the generator); 13: yaw drive (upwind turbines face into the wind; the yaw drive is used to keep the rotor facing into the wind as the wind direction changes; downwind turbines do not require a yaw drive); 14: yaw motor (powers the yaw drive); 15: tower (made of tubular steel or steel lattice, wind speed increases).

\subsection{Fault diagnosis and prognosis}

A fault is a physical defect, imperfection or flaw that occurs within the system. This may cause a failure: the non-performance of some action that is due or expected. 
Table 1 Summary of CMS on WT

\begin{tabular}{|c|c|c|c|}
\hline Part of WT & Fault & Technique & Sensor/monitoring quantity \\
\hline \multirow[t]{2}{*}{ Gear box } & $\begin{array}{l}\text { Gear tooth damages, } \\
\text { bearing faults }\end{array}$ & $\begin{array}{l}\text { Vibration monitoring and spectrum analysis, } \\
\text { supplemented with AE sensing detects } \\
\text { pitting, cracking }\end{array}$ & $\begin{array}{l}\text { Transducers, velocity sensors, } \\
\text { accelerometers, spectral emitted } \\
\text { energy sensors, AE sensors }\end{array}$ \\
\hline & & Oil analysis & Temperature, contamination, moisture \\
\hline Generator & $\begin{array}{l}\text { Stator, bearing, rotor } \\
\text { inside }\end{array}$ & Current signature analysis & Current measurement \\
\hline Rotor blades & $\begin{array}{l}\text { Creep \& corrosion, } \\
\text { fatigue, imbalance, } \\
\text { roughness }\end{array}$ & Shearography, radiography, AE sensing & $\begin{array}{l}\text { AE sensors, strain gauges, Fiber bragg } \\
\text { grating }\end{array}$ \\
\hline Tower and blades & $\begin{array}{l}\text { Ultrasonic testing } \\
\text { techniques }\end{array}$ & $\begin{array}{l}\text { Time-frequency techniques and wavelet } \\
\text { transforms }\end{array}$ & Ultrasonic sensors, Fiber bragg grating \\
\hline $\begin{array}{l}\text { Pitch mechanism, Yaw } \\
\text { system, power electronics/ } \\
\text { electrical system }\end{array}$ & $\begin{array}{l}\text { Voltage and current } \\
\text { analysis, electrical } \\
\text { resistance }\end{array}$ & $\begin{array}{l}\text { Spectrum analysis, eddy current, } \\
\text { thermography }\end{array}$ & $\begin{array}{l}\text { Current and voltage measuring } \\
\text { equipments }\end{array}$ \\
\hline
\end{tabular}

Fault detection is determination of faults that present in a system and time of detection. Fault isolation is determination of kind, location and time of detection of a fault; follows fault detection. Fault identification is determination of size and time-variant behavior of a fault; follows fault isolation and fault diagnosis is determination of kind, size, location and time of a fault; follows fault detection, and includes fault isolation and identification [3]. Prognosis is an approach that combines information on each machine's current condition with historical data from machines of the same class, physics models of failure components and short term projected usage to predict the future probability of failure of that individual machine. That is, prognosis gives a probabilistic forecast that is specific to each machine, allowing a strategy that balances the risk of running a machine with damage indications against the lost revenue while waiting for maintenance [4]. Data mining is a process of extraction of useful information and patterns from huge data. It is also called as knowledge discovery process, knowledge mining from data, knowledge extraction or data /pattern analysis [5]. Various maintenance practices have been described and classified, empirically, into the following approaches [6]: reactive approach, preventive approach, predictive approach, diagnostic (expert systems) approach, autonomous approach, lean approach, proactive approach. The ultimate goal of fault diagnosis and prognosis is to decide the appropriate maintenance strategy.

\subsection{Fault diagnosis and prognosis systems on WT}

Condition monitoring (CM) can detect faults early and prevent major breakdowns. This is associated with significant decrease in maintenance costs. Furthermore, it allows for optimisation of maintenance schedules, thereby reducing downtime and enhancing equipment availability, safety and reliability [7]. García et al provided comprehensive review of the CM of WTs, describing the different maintenance strategies. In their study they have focused their attentions on the sensor technology (acquiring and analysing data for fault diagnosis) [8]. Hameed et al have also provided significant vital information in the area of CM [9, 10]. On a WT major faults are generated because of the main gear box, generator, main bearings, rotor blades and their possibility of failures in terms of percentages are $32 \%, 23 \%, 11 \%$ and less than $10 \%$ respectively as stated by the insurer German Lloyd. The condition monitoring system (CMS) is a tool that provides information on the status of a component and can also predict an expected failure/fault. The possible applications of CMS on WT are shown in the Fig. 1b. The fault diagnoses sensors used and techniques employed for CMS on various parts of the WT are summarized in Table 1 [8-12]. Digital filtering, modeling, signal and spectrum analysis are the main parts of the data processing in CMS. Data analysis in WTs could be based on many techniques, and a few important used techniques are summarized in Table 2. The next step is to predict the remaining life of the components. So as to adopt a suitable maintenance strategy for WTs [13].

Some existing CMS are: Gram \& Juhl TCM system, DMT WindSafe system, Siemens monitoring \& safety system, Prüftechnik [18].

\section{SCADA data based CMS for WT}

Supervisory control and data acquisition (SCADA) is an application that collects data from a system and sends them to a central computer for monitoring and controlling. Current CM systems essentially provide the necessary sensor and capability of data capture required for monitoring. This monitoring system consists of wireless sensors that communicate with an embedded microprocessor mounted on 
Table 2 Summary of sensory signals and signal processing methods [17]

\begin{tabular}{|c|c|c|}
\hline Methods & Description & Applications \\
\hline Statistical methods & $\begin{array}{l}\text { Root mean square, peak amplitude } \\
\text { Maximum value, minimum value, mean, peak to peak, standard } \\
\text { deviation, shape factor, crest factor, impulse factor, definite } \\
\text { integral, energy ratio and kurtosis. }\end{array}$ & $\begin{array}{l}\text { Widely used the diagnosis of } \\
\text { failures }\end{array}$ \\
\hline Trend analysis & Particular algorithms power output patterns from WT generators & $\begin{array}{l}\text { Monitoring pitch mechanisms, } \\
\text { power output generators }\end{array}$ \\
\hline Filtering methods & $\begin{array}{l}\text { Least median squares, filtering with and without a classical } \\
\text { statistical method (based on standard deviation) }\end{array}$ & Vibration filtering \\
\hline Time-domain analysis & $\begin{array}{l}\text { Variations in current signals and trends, vibration analysis, oil } \\
\text { analysis, } \mathrm{AE} \text { analysis }\end{array}$ & $\begin{array}{l}\text { Imbalances between the rotor and } \\
\text { the stator phases, faults in the } \\
\text { rotor windings of the generator }\end{array}$ \\
\hline Cepstrum analysis & Inverse Fourier transform of the logarithmic power spectrum & Gear vibrations \\
\hline Time synchronous averaging (TSA) & Waveform signal & $\begin{array}{l}\text { Cracked gear tooth Identifies } \\
\text { source of error }\end{array}$ \\
\hline Fast-Fourier transform (FFT) & $\begin{array}{l}\text { Conversion of a digital signal from the time domain into the } \\
\text { frequency domain, constant speed wind energy converters. }\end{array}$ & Bearings \\
\hline Amplitude demodulation & $\begin{array}{l}\text { Low-amplitude and low-frequency, periodic signals that might be } \\
\text { masked by other higher energy vibrations }\end{array}$ & Bearings \\
\hline Order analysis & $\begin{array}{l}\text { Out of phase signals can be separated and analysed, suitable for } \\
\text { variable speed wind energy converters }\end{array}$ & $\begin{array}{l}\text { Overall rotor condition including } \\
\text { surface roughness, mass } \\
\text { imbalance and aerodynamic } \\
\text { asymmetry. }\end{array}$ \\
\hline Wavelet transforms & Time-frequency technique, non-stationary signals & $\begin{array}{l}\text { Gears, bearings, mechanical } \\
\text { systems }\end{array}$ \\
\hline Hidden Markov models (HMM) & Classification of patterns in trend analysis & Bearings \\
\hline CI Techniques & Intelligent algorithms [14-16] & All Systems \\
\hline
\end{tabular}

the devices. Its purpose is to allow diagnostic and fault detection algorithms to be deployed down at the sensor/ hardware level. This will decrease the volume of data that must be transmitted and stored via the more traditional centralised SCADA system approach. The SCADA data resides on a server/PC in the form of a database, and the raw data reside on the hard-drive of the microprocessor/sensor system mounted on the turbine (see Fig. 2). A typical SCADA data is 10 min averaged data [19]. Thus the collected and stored SCADA data must then be examined in order to deduce the overall health of the turbine as well as its internal components. An operational wind farm typically generates vast quantities of data. The SCADA data contain information about every aspect of a wind farm, from power output and wind speed to any errors registered within the system [20]. SCADA data may be effectively used to "tune" a wind farm, providing early warnings of possible failures and optimizing power outputs across many turbines in all conditions. Typical parameters recorded by SCADA on a WT could be broadly categorized into following types which could be used in fault diagnosis and prognosis activity: wind parameters, such as wind speed and wind deviations; performance parameters, such as power output, rotor speed, and blade pitch angle; vibration parameters, such as tower acceleration and drive train acceleration; temperature parameters, such as bearing temperature and gearbox temperature [21]. There are some success stories about using SCADA data for CM. Wiggelinkhuizen et al presented the framework of the EU funded condition monitoring for offshore wind farms project. They studied a small wind farm of five turbines having been instrumented with several condition monitoring systems and also with the "traditional" measurement systems for measuring mechanical loads and power performance. Data from vibration and traditional measurements, together with data collected by the turbines' SCADA systems, have been analyzed to assess. They could determine failures, detect early stage of failure and assess the components' health. They developed, applied, and tested several data analysis methods and measurement configurations successfully and concluded that for all types of measurement SCADA data, time series, vibration monitoring could be used for CM [18]. Zaher and McArthur also proposed an idea to use the combination of abnormal detection and data-trending techniques encapsulated in a multi-agent framework for the development of a fault detection system for WTs [19]. 


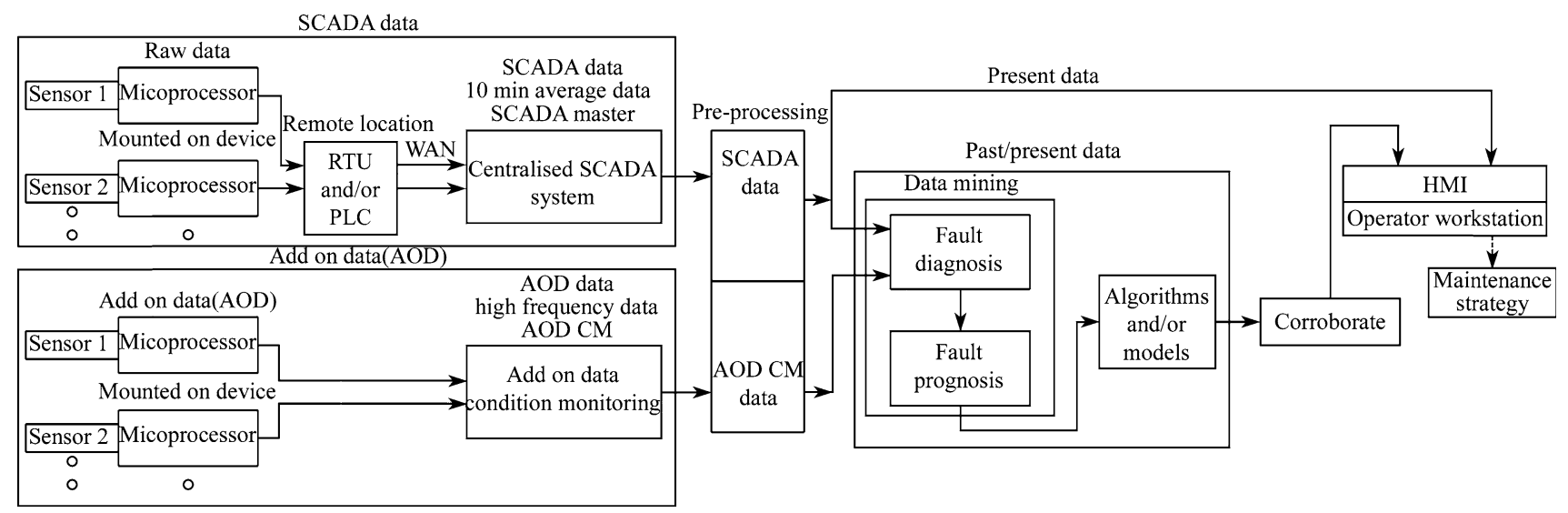

Fig. 2 Proposed intelligent frame work for fault diagnosis and prognosis of WTs

\section{AI methods for analysis of SCADA data from WTs}

Pre-processing of SCADA is a must for extraction of useful information and patterns from huge data. The various AI methods being used for analysis of SCADA data from WTs are artificial neural networks (ANNs), fuzzy systems and combination techniques like adaptive neuro fuzzy inference systems (ANFIS).

\subsection{ANNs}

ANNs can be used for a wide range of applications. They are inspired by the mechanism of the brain and can be classified by different categories as depending upon the learning mechanism or how they are trained (supervised/ unsupervised). ANNs accept input parameters, process them, and produce output parameters according to a nonlinear transfer function. Some of the key features for neural networks (NNs) are their high processing speeds which are due to their massive parallelism, their proven ability to be trained and produce instantaneous and correct responses from noisy or partially incomplete data, and their ability to generalize information over a wide range. These features make them a good choice for applying to WTs' data analysis.

\subsection{Fuzzy systems}

Fuzzy systems are very useful in two general contexts like in situations involving highly complex systems whose behaviors are not well understood and in situations where an approximate, but fast solution is desired. A further advantage of fuzzy systems is that the existing expert knowledge can be implemented to improve the approximation by tuning, removing or adding of membership functions and rules.

\subsection{ANFIS}

Fuzzy neural networks have shown to be very advantageous in dealing with real-world problems. These neurofuzzy systems combine the benefits of these two powerful paradigms into a single capsule. This gives the ability to accommodate both data and existing expert knowledge about the problem under consideration. In ANFIS the advantages of NN are combined with fuzzy inference system (FIS). Thereby the FIS is used to set up a set of rules whose membership function parameters are tuned in a training phase. Recently, Schlechtingen et al have proposed a system for WT condition monitoring using ANFIS. For this purpose, ANFIS normal behavior models for common SCADA data were developed in order to detect abnormal behavior of the captured signals and indicate component malfunctions or faults using the prediction error. They used 33 different standard SCADA signals and described them, for which 45 normal behavior models were developed. The performance of these models was evaluated in terms of the prediction error standard deviations to show the applicability of ANFIS models for monitoring WT SCADA signals. The computational time needed for model training was compared to NN models showing the strength of ANFIS in training speed. For automation of fault diagnosis, FIS was used to analyze the prediction errors for fault patterns. The outputs were both the conditions of the component and a possible root cause for the anomaly. The output was generated by the aid of rules that capture the existing expert knowledge linking observed prediction error patterns to specific faults. The work was based on continuously measured WT SCADA data from 18 turbines of the 2 MW class covering a period of 30 months. The system proposed in this method shows a novel approach with regard to the usage of ANFIS models in this context and the application of the proposed procedure to a wide range of SCADA signals [36]. 


\section{Various algorithms for SCADA data analysis for WTs}

A considerable work has been carried out in using SCADA data on WT diagnosis and prognosis by Kusiak and his group. The works carried out by various researchers are presented in Table 3. Kusiak et al presented various models for monitoring wind farm power output. An evolutionary computation algorithm was used to build a nonlinear parametric model to monitor the wind farm performance. The $k$-NN model produced good performance for the wind farm operating in normal conditions [22]. In their later study, Kusiak et al proposed the concept of anticipatory control applied to WTs. A modified evolutionary strategy algorithm was used to solve a nonlinear constrained optimization problem. The proposed approach has been tested on the data collected from a 1.5 MW WT. In a subsequent study, Kusiak et al proposed a framework for optimization of the power produced by WTs. They proposed control approach generated optimized settings of the blade pitch and yaw angle. They used integration of data mining and evolutionary computation in their approach [23]. In a later study on SCADA data, Kusiak and Zhang found that vibrations of a WT had a negative impact on its performance. Data-mining algorithms were used to build models with turbine parameters of interest as inputs, and the vibrations of drive train and tower as outputs. The performance of each model was thoroughly evaluated based on metrics widely used in the wind industry. The neural network algorithm outperforms other classifiers and is considered to be the most promising approach to study WT vibrations [24]. Ye et al proposed that with design of wind speed difference tests to detect both hard failures (cause complete shutdown of the turbine e.g. gear failure) and soft failures (degrade the turbine performance but do not necessarily stop the turbine e.g. anemometer faults). They used PSO based approach to learn from historical data to decide the location and size of the boundary i.e., abnormal state from the normal state [26]. Further Kusiak et al presented an intelligent WT control system based on models integrating the following three approaches: data mining, model predictive control, and evolutionary computation. The results produced by the intelligent control system were found to be better than those of the current WT control system. For turbulent wind, the intelligent control system smoothed the power output, generator torque, and rotor speed without compromising the electricity demand [25]. Uluyol et al proved that the WT power curve analytic was useful for assessing WT performance and generating robust indicators for component diagnostics and prognostics. This approach makes use of SCADA information and provides easy configuration based on process control approaches for condition-based monitoring. They used operational regime- based condition indicators that prevented false alarms and increased the possibility of fault isolation. This approach could also detect slow performance degradation caused by component wear as well as degradation due to an impending failure [28]. Kusiak and $\mathrm{Li}$ used fault data provided by SCADA system. They carried out fault prediction at three levels: fault and no-fault prediction, fault category (severity), and the specific fault prediction. They used power curve to determine the health of a WT. The model extraction at levels 1 and 3 was performed using $\mathrm{NN}$, the $\mathrm{NN}$ ensemble (NNE), boosting tree algorithm (BTA), and support vector machine (SVM). Whereas at level 2 they used $\mathrm{NN}$, the standard classification and regression tree (CART), the BTA, and the SVM. Furthermore they could successfully predict faults 5-60 min before they occur at each level [29]. Kusiak and Verma used an association rule mining algorithm to identify frequent status patterns of turbine components and systems to predict using historical WT data. They explored five datamining algorithms namely bagging, ripper, rotation forest, random forest, and $k$-nearest neighbor $(k-\mathrm{NN}, k=10)$. They concluded that the best predication results were obtained with random forest algorithm [30]. Zhang and Kusiak proposed three monitoring models for detecting abnormal vibration of WTs in time domain based on SCADA data. The sampling interval of SCADA data was $10 \mathrm{~s}$, and it allowed to detect abnormal statuses of WTs in the time domain. The data collected included training, test, and error data. They used a modified $k$-means clustering algorithm to the first vibration monitoring model. The $k$-means algorithm grouped data into clusters by examining their similarity. The clusters were then labelled as normal or abnormal statuses of WT vibration based on the error reports of WTs. They further incorporated the concept of control charts to develop models for monitoring of turbine vibration. They also addressed the detecting of abnormal drive train and tower vibration of a WT. They compared seven different data-mining algorithms, namely, NNE, NN, boosting regression tree (BT), SVM, random forest with regression (RF), CART, and $k$-NN. Four metrics, the mean absolute error (MAE), standard deviation of absolute error (SD of AE), mean square error (MSE), and the standard deviation of square error (SD of SE), are utilized to evaluate the performance of data-mining algorithms in model extraction. They found that the NNE model was recognized as the most suitable model for determining drive train acceleration and the $\mathrm{NN}$ model was considered to be the most suitable algorithm for developing the model for predicting tower acceleration [31]. Yang et al in their work proposed a technique which would interpret the SCADA data collected from WTs. They developed an effective method for processing raw SCADA data, further proposed an alternative condition monitoring technique based on 


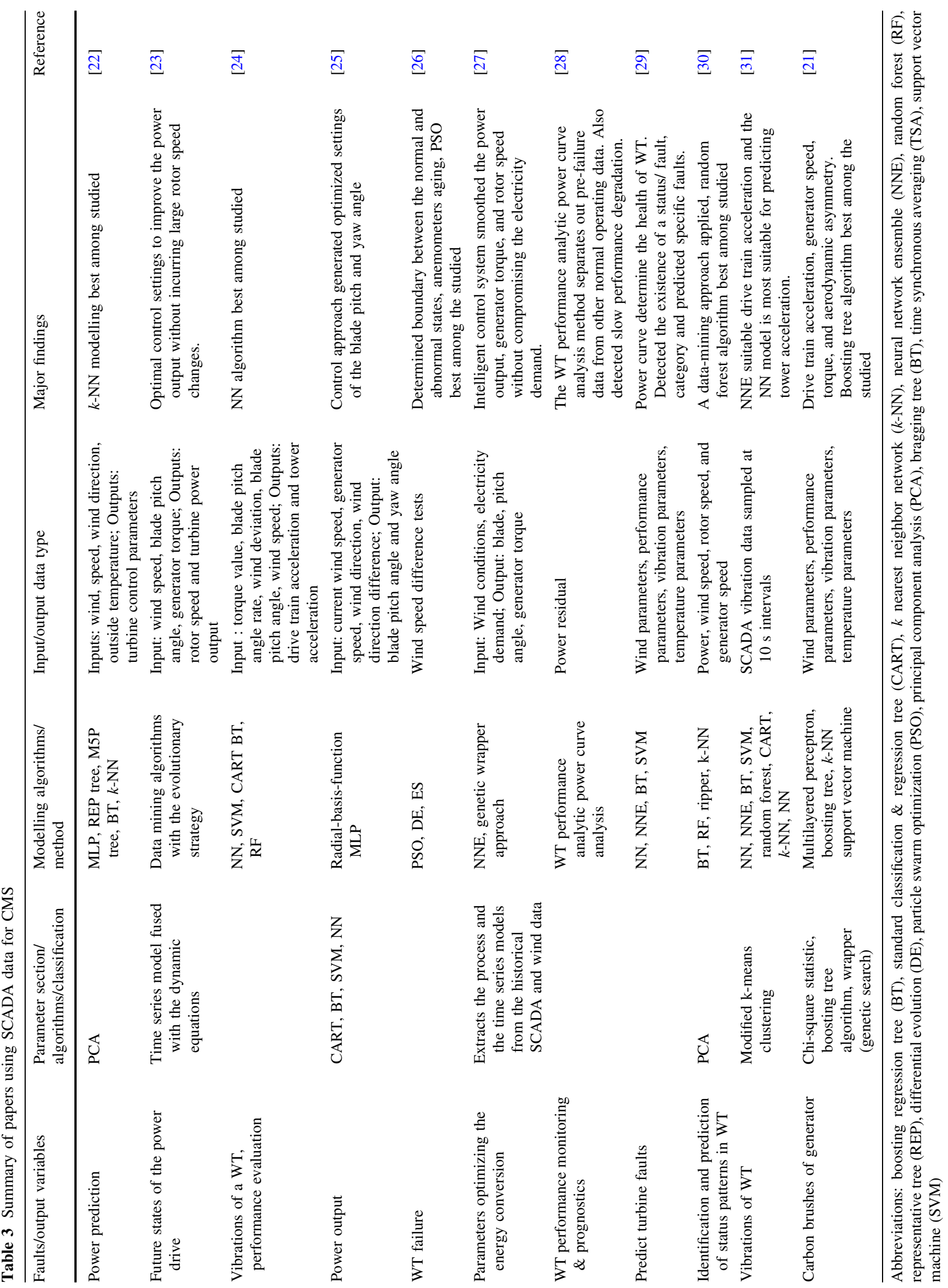


investigating the correlations among relevant SCADA data; and realized the quantitative assessment of the health condition of a turbine under varying operational conditions. Both laboratory and site verification tests had been conducted and were found satisfactory [32].

\section{Discussions and future challenges}

From the literature reviewed it has been demonstrated successfully by researchers that by keeping track of wind speed and power output parameters, the overall health of the turbine can be supervised. Furthermore, SCADA data could be usefully used for CM of WTs and locating faults. There has been success in using SCADA data for power prediction, optimal control settings, performance evaluation, predicting turbine faults (predicting drive train acceleration/tower acceleration/gear box failure) and also the vibrations on a WT. Many AI techniques have been applied including NN, Fuzzy, ANFIS, GA's etc [32, 33], AI model in CM of WTs is justifiable as there are many variables involved and it is not easy to establish accurate mathematical model for such kind of complicated systems. It is also proposed to use data fusion techniques for monitoring the health of WTs' [34]. Few challenges that need to overcome before SCADA data analysis becomes fully successful are: SCADA data can differ from turbine to turbine and SCADA data change with the operational conditions. So because of this it becomes difficult to differentiate between a real fault and fake fault which is quite a challenge.

Moreover WT SCADA data are usually $10 \mathrm{~min}$ average data, so some information is lost. Thus referring to the research of WT condition monitoring, a frame work is proposed that takes SCADA data and also an add on high frequency data from the sensors (some) to diagnose and prognose with both conventional data and SCADA data. After comparison of the two results, the appropriate method can be chosen for maintenance decision making.

A number of models have been proposed, then tried and tested $[35,36]$, accuracy of the model depends upon the careful selection of variables and the quality of the data (free from noise). So pre-processing of the data plays an important role in the accuracy of the models. Performances of AI based data mining algorithms and CM algorithms are showing quite promising results. Hence by using computational intelligence concepts more efficient models could be obtained thus enhancing the accuracy and robustness of the model. It is proposed that data mining (AI based) and evolutionary computations could be integrated for building the models for prediction and monitoring.

\section{Conclusions}

The major outcomes from this study are listed below:

A frame work is proposed for diagnosing and prognosing of CM of WTs using a combinational approach. These make use of conventional SCADA data and add on high frequency data from the sensors. In addition to this it also analyses historical SCADA data.

Few challenges that need to overcome in SCADA data analysis are: firstly SCADA can differ from turbine to turbine, secondly SCADA data change with the operational conditions. So pre-processing the raw data can equally contribute to the success of the CM algorithm itself.

Some researchers have successfully demonstrated the use of AI algorithms for SCADA data analysis. Seeing their performance it is believed that AI models could enhance the accuracy and robustness of models.

Though the comparison results of various models are mentioned but no clear cut perfect modeling technique could emerge. So this area remains open for further explorations.

\section{References}

1. Kaldellis JK, Zafirakis D (2011) The wind energy (r)evolution: a short review of a long history. Renew Energy 36:1887-1901

2. Kusiak BA, Verma A (2010) The future of wind turbine diagnostics. windsystemsmag.com, pp 66-71

3. Donders S (2002) Fault detection and identification for wind turbine systems: a closed-loop analysis. Dissertation, University Twente

4. Hyers RW, Mcgowan JG, Sullivan KL et al (2006) Condition monitoring and prognosis of utility scale wind turbines. Energy Mater Mater Sci Eng Energy Syst 1:187-203

5. Ramageri BM (2010) Data mining techniques and applications. Indian J Comput Sci Eng 1:301-305

6. Alsyouf I (2004) Cost effective maintenance for competitive advantages. Dissertation, Växjö University, Sweden

7. Entezami M, Hillmansen S, Weston P, Papaelias MP (2012) Fault detection and diagnosis within a wind turbine mechanical braking system using condition monitoring. Renew Energy 47:175-182

8. Lu B (2009) A review of recent advances in wind turbine condition monitoring and fault diagnosis. In: IEEE symposium on power electronics and machines in wind applications, pp 1-7

9. Hameed Z, Hong YS, Cho YM (2009) Condition monitoring and fault detection of wind turbines and related algorithms: a review. Renew Sustain Energy Rev 13:1-39

10. Hameed Z, Ahn SH, Cho YM (2010) Practical aspects of a condition monitoring system for a wind turbine with emphasis on its design, system architecture, testing and installation. Renew Energy 35:879-894

11. Fischer K, Besnard F, Bertling L (2012) Reliability-centered maintenance for wind turbines based on statistical analysis and practical experience. IEEE Trans Energy Convers 27:184-195 
12. Liu WY, Zhang WH, Han JG et al (2012) A new wind turbine fault diagnosis method based on the local mean decomposition. Renew Energy 48:411-415

13. Nadakatti M, Ramachandra A, Kumar ANS (2008) Artificial intelligence-based condition monitoring for plant maintenance. Assem Autom 28:143-150

14. Lei Y, Lin J, He Z et al (2012) A method based on multi-sensor data fusion for fault detection of planetary gearboxes. Sensors 12:2005-2017

15. Amjady N, Hedayatshodeh M (2012) A new power transformer fault diagnosis system and its application for wind farms. J Basic Appl Sci Res 2:4758-4764

16. Uraikul V, Chan CW, Tontiwachwuthikul P (2007) Artificial intelligence for monitoring and supervisory control of process systems. Eng Appl Artif Intell 20:115-131

17. García Márquez FP, Tobias AM et al (2012) Condition monitoring of wind turbines: techniques and methods. Renew Energy 46:169-178

18. Wiggelinkhuizen E, Verbruggen T, Braam H et al (2008) Assessment of condition monitoring techniques for offshore wind farms. J Sol Energy Eng. doi:10.1115/1.2931512

19. Zaher AS, McArthur SDJ (2007) A multi-agent fault detection system for wind turbine defect recognition and diagnosis. IEEE Lausanne Power Tech 2007:22-27

20. Kim K, Parthasarathy G, Uluyol O et al (2011) Use of SCADA data for failure detection in wind turbines. In: Conference Paper, NREL/CP-5000-51653, October 2011

21. Verma A, Kusiak A (2012) Fault monitoring of wind turbine generator brushes: a data-mining approach. J Sol Energy Eng. doi:10.1115/1.4005624

22. Kusiak A, Zheng H, Song Z (2009) Models for monitoring wind farm power. Renew Energy 34:583-590

23. Kusiak A, Song Z, Zheng H (2009) Anticipatory control of wind turbines with data-driven predictive models. IEEE Trans Energy Convers 24:766-774

24. Kusiak A, Zhang Z (2010) Analysis of wind turbine vibrations based on SCADA data. J Sol Energy Eng. doi:10.1115/1.4001461
25. Kusiak A, Zheng H, Song Z (2010) Power optimization of wind turbines with data mining and evolutionary computation. Renew Energy 35:695-702

26. Ye X, Yan Y, Osadciw LA (2010) Learning decision rules by particle swarm pptimization (PSO) for wind turbine fault diagnosis. In: Proceedings of annual conference of the prognostics and health management society, Portland, OR, Oct 10-14, 2010

27. Kusiak A, Li W, Song Z (2010) Dynamic control of wind turbines. Renew Energy 35:456-463

28. Uluyol O, Parthasarathy G, Foslien W et al (2011) Power curve analytic for wind turbine performance monitoring and prognostics. In: Proceedings of annual conference of the prognostics and health management society, pp 1-8

29. Kusiak A, Li W (2011) The prediction and diagnosis of wind turbine faults. Renew Energy 36:16-23

30. Kusiak A, Verma A (2011) Prediction of status patterns of wind turbines: a data-mining approach. J Sol Energy Eng. doi:10.1115/ 1.4003188

31. Zhang Z, Kusiak A (2012) Monitoring wind turbine vibration based on SCADA data. J Sol Energy Eng 134:021004

32. Yang S, Li W, Wang C (2008) The intelligent fault diagnosis of wind turbine gearbox based on artificial neural network. In: Proceedings of international conference on condition monitoring and diagnosis, pp 1327-1330

33. Garcia MC, Sanz-Bobi MA, del Pico J (2006) SIMAP: intelligent system for predictive maintenance. Comput Ind 57:552-568

34. Dempsey PJ, Sheng S (2013) Investigation of data fusion applied to health monitoring of wind turbine drivetrain components. Wind Energy 16(4):479-489

35. Wilkinson M, Darnell B, Harman K (2013) Presented at EWEA 2013 annual comparison of methods for wind turbine condition monitoring with SCADA data. EWEA 2013 annual event, Vienna, pp 4-7

36. Schlechtingen M, Ferreira Santos I (2011) Comparative analysis of neural network and regression based condition monitoring approaches for wind turbine fault detection. Mech Syst Signal Process 25:1849-1875 